\title{
Comunicación y deporte en la era digital ${ }^{*}$
} Sinergias, contradicciones y responsabilidades educativas

\author{
Miquel DE MORAGAS SPÀ
}

\section{INTRODUCCIÓN. LA CORRESPONSABILIDAD EN LA COMUNICACIÓN: DEPORTE Y MASS MEDIA}

Al referirnos aquí a las relaciones entre los medios de comunicación y el deporte pensamos, directamente, en dos principales aspectos:

- La responsabilidad cultural que comparten mass media e instituciones deportivas.

- La atención desmesurada que los medios de comunicación prestan al deporte espectáculo, en detrimento del deporte para todos, del deporte entendido como práctica deportiva.

En este artículo nos proponemos analizar la cuestión desde una doble perspectiva, que incluya la corresponsabilidad de los medios y de las instituciones deportivas. Entendiendo que esto debe enfocarse así porque en la sociedad actual las relaciones entre comunicación y deporte, sus sinergias, son cada vez más estrechas.

Desde esta perspectiva, las preguntas que con frecuencia se dirigen desde el mundo del deporte a los medios de comunicación no parecen siempre bien dirigidas. A quién debemos dirigir preguntas tales como: ¿qué hacen ustedes con los valores educativos del deporte? o ¿qué atención prestan ustedes al deporte para todos? Las instituciones deportivas pueden formular legitimamente estas preguntas a los medios de comunicación, pero las mismas razones asisten a los medios de comunicación para formular estas mismas preguntas a las instituciones deportivas.

* La investigación básica para este artículo se ha realizado con el apoyo del Programa de Investigación de la DGICYT, Ministerio de Educación, España. Una primera versión de este artículo fue presentada al Congreso Mundial de Deporte para Todos celebrado en Barcelona en octubre de 1998. 
La responsabilidad de la construcción (o deconstrucción) de los valores relacionados con el deporte corresponde solidariamente a los nuevos conglomerados formados entre los mass media, especialmente las televisiones, los patrocinadores y las organizaciones deportivas. O lo que viene a ser lo mismo: las responsabilidades de comunicación, directa e indirectamente, no corresponden únicamente a las instituciones de comunicación sino que también corresponden a las instituciones deportivas, cada vez más responsables de la producción simbólica y de la información deportiva.

Este nuevo protagonismo compartido entre comunicación (mass media/patrocinio) y deporte, no parece haber desplegado todavia todas sus posibilidades. La transformación tecnológica de los procesos de producción y difusión de la información en la nueva sociedad informacional facilitará, aún más, estos procesos de convergencia, abriendo nuevos riesgos pero también nuevas oportunidades a las instituciones deportivas.

¿Los riesgos?: la pérdida de autonomía respecto de los medios de comunicación. ¿Las oportunidades?: la posibilidad de convertirse, ellas mismas, las instituciones deportivas, en medios de comunicación.

\section{LAS NUEVAS FORMAS SIMBÓLICAS DEL DEPORTE: ¿ACTIVIDAD FÍSICA, ESPECTÁCULO, MASS MEDIA O "JUEGO VIRTUAL"?}

En nuestros dias hablar de deporte significa hablar de una gran diversidad de fenómenos, de naturaleza claramente diferente, pero enlazados entre si a través de significados compartidos.

Los ideólogos del "deporte para todos", conscientes de la importancia de la actividad fisica, podrán preguntarse legítimamente: ¿qué tiene que ver el deporte con la obesidad acumulada en un sofá, durante horas y horas, comiendo palomitas de maíz, bebiendo cerveza y consumiendo programas deportivos en televisión? Este comportamiento no tiene nada que ver con la actividad física y, sin embargo, tiene mucho que ver con las funciones culturales del deporte en la sociedad contemporánea.

Por esto proponemos distinguir hasta cuatro principales niveles de práctica simbólica del deporte en la sociedad actual:

- el "deporte actividad física", nivel en el que se sitúa el "deporte para todos"; 
- el "deporte espectáculo";

- el "deporte en los mass media";

- el "deporte virtual".

Se trata, desde luego, de fenómenos de naturaleza bien distinta, pero el análisis demostrará que existen múltiples sinergias entre todas estas variantes de "deporte", organizadas en torno a una influencia y a una lógica dominante: la de los mass media.

Sólo algunos ejemplos introductorios:

El "deporte en los mass media" (o "deporte mediático") se ha convertido en una de las principales formas de entretenimiento en las sociedades modernas y, por consiguiente, en una fuente de ingresos hasta ahora desconocida para las empresas de televisión, los patrocinadores y las organizaciones deportivas. La práctica deportiva profesional está absolutamente condicionada por este proceso.

Pero el "deporte en los mass media" también ha influido en los espectadores, en sus formas de ver el deporte. Hasta la aparición de la televisión y, más en concreto, hasta la generalización de las transmisiones deportivas, la única forma de ver el deporte era participando del "deporte espectáculo", asistiendo a las pruebas, interactuando, de alguna forma, con los deportistas y creando comportamientos de masas.

Esta forma de participar y, sobre todo, de ver el deporte ha cambiado radicalmente con la aparición de la televisión. El "deporte en los mass media" es claramente distinto del "deporte espectáculo". En algunos casos los espectadores del "deporte espectáculo" se han convertido en meros decorados, actores, del "deporte en los mass media".

¿Quién podía imaginar, hace unos años, que un gol podría verse repetido desde los más insólitos puntos de vista? Las cámaras de televisión han transformado la mirada humana, la extensión de los sentidos (como dijo McLuhan), y el deporte ha sido un escenario privilegiado para esta experiencia.

El deporte moderno, la práctica del deporte y el espectáculo deportivo en nuestros días están incuestionablemente influidos por esta nueva mirada de la televisión. Los niños juegan, visten prendas deportivas, gesticulan, interactúan de acuerdo con lo que ven en los estadios, pero sobre todo con lo que ven en las pantallas de televisión.

Esta transformación de las formas de ver y de vivir simbólicamente el deporte está muy lejos de haber terminado su ciclo. Más bien parece que nos encontramos al principio de una nueva etapa cuyas consecuencias sólo podemos entrever en algunas experiencias pioneras. Es lo que propongo denominar "deporte virtual". 
Ya no se trata de ver -a través de los medios- aquello que sucede en los estadios ante unos espectadores-actores, sino que ahora se trata de "inventar" el acontecimiento deportivo. Es el caso de los juegos deportivos informáticos, en los que se puede crear jugadores, estadios, condiciones atmosféricas, para producir una experiencia deportiva virtual.

No se trata de futuribles sino de productos en expansión en nuestra sociedad-red: juegos informáticos deportivos, webs deportivas, entretenimientos deportivos multimedia.

Esta tendencia a la ficción, a la invención deportiva, también afecta al deporte "en los mass media". Cada vez es más frecuente ver cómo los broadcasters tienden a ignorar o a esconder la condición de "directo" o "diferido" en sus transmisiones deportivas, a interrumpirlas con nuevas fórmulas multimedia, gráficas o estadísticas, a incluir publicidad virtual en las transmisiones... a transformar el "acontecimiento" en un producto audiovisual.

\section{LAS NUEVAS SINERGIAS ENTRE EL DEPORTE Y LA COMUNICACIÓN}

\section{La influencia del deporte en los mass media}

Hasta finales de los años setenta la influencia entre los medios de comunicación y el deporte se analizaba únicamente en una sola dirección: la de la influencia de la comunicación sobre el deporte.

Ya en los años ochenta, a medida que el deporte empieza a convertirse en uno de los géneros básicos de la programación de los canales de televisión, esta influencia se hace sentir, cada vez más intensamente, en la dirección contraria: en el sentido de la influencia del deporte sobre los medios de comunicación.

La influencia del deporte sobre la televisión se deja sen-

1. De Moragas, Miquel. Los juegos de la comunicación. Madrid: Fundesco, 1992.

De Moragas, Miquel, y Nancy Rivenburgh. Television in the Olympics. London: John Libbey, 1995. tir en muy diversos sectores (tecnología, programación, audiencia, economía, etc.) y se convierte en un aspecto fundamental de las estrategias de competitividad de las empresas de televisión, en una etapa crucial de lucha por la hegemonía en todos los mercados audiovisuales del mundo.

El deporte como consecuencia de su dimensión global, ha sido uno de los principales protagonistas de los procesos de implantación de las tecnologias audiovisuales contemporáneas (video doméstico, transmisión satélite, cámaras especiales, etc.) ${ }^{1}$. 
La popularidad y consolidación de algunas cadenas de televisión se ha debido, en gran parte, a su habilidad para conseguir los derechos de transmisión y cobertura de los grandes acontecimientos deportivos (Juegos Olimpicos, campeonatos mundiales, ligas profesionales, etc.)

Con respecto a la programación debe señalarse que el deporte constituye una fuente inagotable de noticias de gran interés popular, de alguna manera alternativas a las informaciones de actualidad siempre más conflictivas. Pero el deporte es también, y fundamentalmente para la televisión, una fuente inagotable de programas. En 1995 el deporte representaba aproximadamente el $10 \%$ del tiempo total de programación del conjunto de los canales de televisión en Europa. Y lo que es más importante, el deporte facilita a la televisión grandes récords de audiencia.

El deporte ofrece, pues, numerosas ventajas y atractivos a los programadores de la televisión. Les proporciona programas relativamente baratos, de limitada complejidad productiva y de alta rentabilidad dadas sus audiencias, representa importantes valores añadidos para las estrategias de las cadenas de televisión y para sus anunciantes.

Las nuevas condiciones de la "ecología de la comunicación" (multiplicación de canales, necesidad de rapidez en la percepción de los mensajes publicitarios, necesidad de segmentación de los públicos, mayores exigencias de espectacularidad, competitividad entre cadenas, alternancia en el interés por lo local y lo global, pay per view, etc.) reforzarán, aun más en el futuro, esta aportación del deporte a la televisión.

Tampoco podemos ignorar que nos encontramos en una fase histórica de cambios en la comunicación, en una fase de tránsito de la era broadcasting a la era webcasting, todo lo cual exige a las empresas de comunicación una adaptación apresurada, sin apenas tiempo para la experimentación. En este nuevo contexto la televisión deportiva, apoyada en el alto grado de fidelización de sus audiencias, se convierte en un campo privilegiado de experimentación para retos tan importantes como:

- Afrontar la multiplicación de canales en casi todos los mercados televisivos del mundo.

- Adaptar la programación, especialmente de las cadenas generalistas, a la creciente segmentación de las audiencias.

- Encontrar nuevas formas de percepción de los mensajes publicitarios.

- Obtener mayores cotas de espectacularidad de los programas. 
- Fidelizar a los públicos en temas esenciales de su representación de identidad.

- Introducir y experimentar el pay per view.

- Introducir y experimentar el webcasting (o televisión por internet), etc.

El futuro de los medios, por lo menos en esta etapa de transformaciones, no puede imaginarse al margen de estas importantes sinergias. Los mass media ya no se limitan a "informar" sobre el deporte y sobre las instituciones deportivas. Los medios se han convertido en verdaderos actores y productores de las nuevas formas culturales del deporte.

\section{La influencia de los mass media en el deporte}

Hasta los años setenta el deporte mantuvo una cierta autonomía respecto de los mass media. Éstos influían en el deporte del mismo modo como podían hacerlo sobre otras instituciones sociales, como la economía, la política o la cultura.

Pero estas influencias cambiaron radicalmente cuando los medios desbordaron el ámbito de la "información sobre el deporte" para empezar a ser protagonistas ellos mismos del deporte con las transmisiones en directo. Desde este momento los mass media no sólo fueron intérpretes o informadores de las actividades deportivas, sino que se convirtieron en auténticos coautores. Para decirlo de una forma expresiva: los cambios empezaron a ser radicales cuando los estadios se convirtieron en sets de televisión.

Estos cambios tienen una primera consecuencia: la aparición de un fenómeno verdaderamente nuevo en la historia del deporte; la creación de nuevos conglomerados mediático-deportivos. Ejemplos: El primero y más destacado en Europa fue la compra por parte de Berlusconi, entonces "magnate" de la televisión, de uno de los clubes de fútbol más importantes de Italia, el AC Milan. Mientras escribo estas líneas, otro "magnate" de la televisión, Murdoch, ofrece un total de 625 millones de libras (algo más de mil millones de dólares) por la compra del Manchester United. Las manifestaciones de protesta de los aficionados no parecen tener el soporte de los medios de comunicación.

Estos cambios tienen múltiples consecuencias -económicas, culturales, organizativas- sobre la estructura del deporte moderno.

Las instituciones deportivas pierden autonomía respecto de los nuevos negocios de la comunicación. Se inician nu- 
merosos procesos de adaptación del deporte a las exigencias de los medios y especialmente a las exigencias de la televisión. Se empieza por adoptar los calendarios deportivos nacionales e internacionales a las exigencias del calendario de la televisión, se busca la periodización y se evita el cruce entre acontecimientos, se internacionaliza el calendario, los deportes occidentales se popularizan en los países orientales, la llegada de la televisión cambia en muchos países el índice de popularidad de los deportes. Poco a poco se produce la adaptación de los horarios del deporte a las exigencias o prioridades horarias de la televisión, especialmente al prime time.

Otra importante influencia de los mass media se manifiesta en la nueva jerarquización de los deportes. La popularidad de éstos ya no viene determinada por el espectáculo deportivo propiamente dicho, sino por la espectacularidad de las imágenes televisivas, por su "televisibilidad". Un buen ejemplo de ello lo constituyen los saltos de trampolin (diving) que de nuevo en Atlanta han alcanzado los primeros puestos en las audiencias de los Juegos Olímpicos.

\subsection{La influencia económica}

Pero la influencia de los mass media sobre el deporte tiene su eje principal en la transformación de la economía de las instituciones deportivas. Una clara prueba de esta nueva lógica la encontramos en el caso de las dimensiones alcanzadas por el patrocinio y los derechos de transmisión televisiva de los Juegos Olímpicos.

Nos interesa destacar aquí las grandes aportaciones de las cadenas norteamericanas de televisión para obtener los derechos de transmisión de los Juegos Olimpicos durante las décadas de los años setenta y ochenta, en comparación con las limitadas cantidades aportadas por el resto de cadenas internacionales.

Esto debe explicarse por la alta competitividad interna existente en el sistema televisivo de Estados Unidos, a diferencia de lo que sucedia en Europa con un sistema televisivo centralista y monopólico. Pero tan significativo como esto es el gran incremento de los derechos pagados por las cadenas de televisión europeas, a partir, precisamente, de la desregulación y de la aparición de los canales privados.

Desde entonces, estos canales de televisión (a través de la European Broadcasting Union, EBU), sin llegar todavía a las cotas de las cadenas norteamericanas, aceptan grandes incrementos, de hasta el $400 \%$ entre ediciones, para adquirir 
los derechos de los Juegos Olímpicos de Seúl '88, Barcelona ‘92, Atlanta '96 y Sydney 2000 (véase cuadro $N^{\circ} 1$ ).

\section{Cuadro $N^{\circ} 1$}

Evolución de los derechos de televisión de los Juegos Olímpicos de Verano (1980-2008). Participación de la NBC (EE UU) y la European Broadcasting Union (EBU) (en millones de US\$)

\begin{tabular}{lcccc}
\hline & NBC & $\begin{array}{l}\text { Incremento } \\
\text { entre ediciones } \\
\text { consecutivas }\end{array}$ & $\begin{array}{l}\text { EBU } \\
\text { Incremento } \\
\text { entre ediciones } \\
\text { consecutivas }\end{array}$ \\
\hline Moscú 1980 & 85 & & 7,1 & \\
Los Ángeles 1984 & 225 (ABC) & $165 \%$ & 19,8 & \\
Seúl 1988 & 300 & $33 \%$ & 28 & $41 \%$ \\
Barcelona 1992 & 401 & $34 \%$ & 90 & $221 \%$ \\
Atlanta 1996 & 456 & $14 \%$ & 255 & $183 \%$ \\
Sydney 2000 & 705 & $55 \%$ & 350 & $37 \%$ \\
Atenas 2004 & 793 & $12 \%$ & 394 & $13 \%$ \\
Juegos 2008 & 894 & $13 \%$ & 443 & $12 \%$ \\
& & & & \\
Total 1980-2008 & 3.859 & & $1.586,9$ & \\
\hline
\end{tabular}

Fuente: IOC, 1996 Olympic Marketing Fact File, Marketing Departament, IOC.

Por su parte, la NBC, que había adquirido la exclusiva de los Juegos Olímpicos de Verano desde Sydney 2000 hasta el año 2008 por un total de 2.392 millones de dólares, cerraba sus cuentas de Atlanta con un espectacular éxito de audiencias y unos beneficios calculados en decenas de millones de dólares, más los beneficios indirectos de posicionamiento en la lucha por la hegemonía televisiva en su mercado audiovisual.

La historia de estos incrementos y las grandes sumas invertidas por las cadenas de televisión tienen una principal clave interpretativa: el precio de las audiencias y la alta competitividad audiovisual que caracterizan a nuestra época. Pero tienen una segunda consecuencia: la transformación de los deportes más populares en deportes "mediáticos". 
3. Efectos culturales de las nuevas sinergias entre mass media $y$ deporte

La televisión afecta la regulación de los deportes, los criterios de profesionalidad, la economía de los clubes y federaciones, los calendarios, la duración de las competiciones (tie break); afecta, en su conjunto, la estructura del deporte moderno y las formas culturales de la relación entre los ciudadanos y el deporte.

La más importante de estas influencias consiste en la creación de universos simbólicos de identificación y de exclusión. Los mass media contribuyen, por ejemplo, a incrementar notablemente el triunfalismo de la victoria, pero también el dramatismo de la derrota. Conseguir la cuarta o quinta posición en unos Juegos Olímpicos, perder un partido en el Campeonato Mundial de Fútbol, puede llegar a ser vivido como un fracaso... nacional.

Los mass media han traspasado al deporte las formas narrativas de la ficción y del entretenimiento. Se narra el deporte como se narra una telenovela (soap opera). Recuérdese, por ejemplo, el caso de las patinadoras Nancy Kerrigan (buena y bella) y Tonya Harding (mala y conflictiva) en Lillehammer, romance o drama deportivo que constituyó un nuevo récord de audiencia en la historia de la televisión norteamericana. Las cotas de audiencia alcanzadas por las patinadoras sólo han sido superadas por otras transmisiones deportivas (tres finales del Superbowl) o por los últimos y cruciales capítulos de algunas grandes teleseries (Mash o Dallas). Telenovelas y deporte se sitúan a la cabeza de la historia de las audiencias de la televisión.

Estas sinergias también contribuyen a la pérdida de independencia por parte de los medios respecto de la información deportiva. Algunos comentaristas dejan de ser propiamente periodistas y reporteros para convertirse, más bien, en narradores implicados en el espectáculo, del mismo modo, algunos comentaristas de televisión, influenciados por los altos costos de la adquisición de derechos, narran con mucha euforia para mantener las audiencias. Todos los partidos son ahora "los partidos del siglo".

Lo más importante es que ningún telespectador tome el control remoto para cambiar de canal.

El tratamiento televisivo dado por la NBC a los Juegos de Atlanta (posproducción, cortes publicitarios, cortes para introducir videos y comentarios personalizados) se distanciaba decididamente de los estilos clásicos de transmisión de los acontecimientos deportivos. 
2. NBC. Games XXVI Olympiad, Atlanta: Press Dossier, 1996.

3. Incluso la prensa norteamericana manifestó su preocupación por esta nueva forma de "producir los Juegos" por parte de la televisión.

"So in an era when television technology can show almost any happening in real time, NBC has perversely used that technology to create as a zone of fictional time (...) NBC has been going where no network has gone before in ignoring the athletes from the rest of the world (...) The Olympic Games for all their entertainment value, are still news, not a made-for-Tv Movie". Editorial del New York Times, 2 de agosto de 1996.
La "transmisión deportiva" se veía sustituida por una "narración deportiva" en la que el deporte se convertía en un pretexto para contar historias.

NBC's policy is that no results will be revealed on air until the event has been played out in the telecast. This will allow viewers to enjoy the event as if it were live and allow for the drama to logically unfold ${ }^{2}$.

Los mismos directivos de la NBC no disimularon su estrategia y presentaron abiertamente su propia filosofia, resumida en lo que denominaron "cinco anillos" de su retórica, a saber: "historia", "realidad", "posibilidad" (algo alcanzable), "idealismo" y "patriotismo"3.

Los índices de audiencia de la NBC en los Juegos de Atlanta confirmaron el éxito comercial de estas estrategias.

\subsection{El deporte, escenario privilegiado para la producción simbólica}

Este nuevo juego de relaciones entre comunicación y deporte ofrece a las instituciones deportivas la posibilidad -y la responsabilidad- de convertirse y de actuar como verdaderas instituciones culturales de gran influencia mundial.

La estrecha relación entre el deporte y los medios de comunicación han convertido al deporte y a los acontecimientos deportivos en grandes escenarios de producción simbólica. Se traspasa así a las organizaciones deportivas una nueva y gran responsabilidad cultural: la de la producción de los valores en el escenario de los grandes acontecimientos mediáticos de la era moderna.

Un ejemplo destacado de esta responsabilidad y de estas posibilidades, lo tenemos en el caso de las ceremonias olímpicas, espectáculos que, hoy por hoy, mantienen el récord de las máximas audiencias posibles en la televisión mundial. Los organizadores olímpicos se han convertido así en los productores de los más grandes espectáculos culturales de nuestra época. El deporte para todos, pero también la estimación de las diferencias culturales, la promoción de la igualdad y de la cultura de la paz, tienen en estas ceremonias un escenario incomparable.

Una mención muy especial merece el caso de los Juegos Paralímpicos y su contribución a la integración de todas las personas en el deporte de elite y, como consecuencia simbólica, a su integración a la vida social moderna. 
Pero la producción simbólica no debería quedar reflejada únicamente en las "ceremonias", sino también y sobre todo en el desarrollo de los acontecimientos deportivos, en los que las imágenes de los gestos, de las relaciones entre atletas y público, las imágenes del público y de sus símbolos, constituyen un escenario de producción de simbolos especialmente influyente.

Estas formas simbólicas serán objeto de comentario y de crítica por parte de los medios de comunicación, pero también serán objeto de la máxima atención por parte de las instituciones educativas, escuelas, universidades, que han de llevar el deporte a sus campos de juego y también lo llevarán a sus aulas como tema de estudio, como objeto central del sistema de valores en nuestra cultura.

\section{EL DEPORTE PARA TODOS Y SU PROMOCIÓN. SABER USAR LOS MEDIOS}

Hemos visto cómo las instituciones deportivas se van convirtiendo, cada día más, en productores de símbolos y en actores de la comunicación, con una relación cada vez más estrecha con los mass media.

Nuestro análisis de las experiencias de deportes para todos (véase la base de datos Edusport ${ }^{4}$ ) pone de relieve una atención de los medios de comunicación por estas experiencias mucho mayor de lo que comúnmente se reconoce. Hasta un $80 \%$ de las experiencias analizadas manifiestan haber utilizado por lo menos uno de los tres grandes medios (prensa, radio o televisión) en sus estrategias de comunicación.

Creemos que esto debe interpretarse como el resultado de un proceso de cooperación entre los promotores del deporte para todos y los responsables de los medios de comunicación, receptivos a las informaciones que aquéllos les suministran.

La gran mayoria de las experiencias de deporte para todos utilizan los medios de comunicación para la difusión de sus actividades, desde los casos más minoritarios que únicamente utilizan murales, folletos o carteles, hasta los casos verdaderamente relevantes de uso de todos los mass media e incluso de internet.

Un número considerable de experiencias (el 18\%) declara utilizar todos los medios de comunicación disponibles (carteles, folletos, radio, prensa, televisión e internet).

El 90\% de las experiencias analizadas declara utilizar folletos y/o carteles para la difusión de sus proyectos. Hasta
4. La base de datos Edusport ofrece información sistemática de experiencias internacionales de deporte para todos. En el momento de cerrar este trabajo Edusport incluía información sobre 125 experiencias. Edusport es accesible a través de la web del Centre d'Estudis Olimpics i de l'Esport de la UAB.

http://www.blues. uab.es/olympic. studies 
un $47 \%$ utilizan la televisión, mientras que la prensa y la radio son utilizadas, respectivamente, por el $67 \%$ y el $58 \%$ de las experiencias analizadas. Como hemos visto, hasta un $80 \%$ de las experiencias declaran haber utilizado por lo menos uno de los tres mass media para la promoción de sus actividades.

Las claves del éxito, en este terreno, parecen estar en la capacidad y la imaginación de las instituciones deportivas para crear iniciativas capaces de interesar a los medios de comunicación. Pero ésta sólo es una cara de la moneda, la otra cara consiste en la capacidad de estas instituciones para crear sus propios instrumentos de comunicación, lo cual es cada vez más asequible gracias a las nuevas tecnologías de autoedición y a la comunicación por internet.

Las instituciones deportivas no deben limitarse, pues, a esperar a que los medios de comunicación pongan atención en sus actividades, sino que deben empezar a considerarse ellas mismas como verdaderos medios y emisores de comunicación. En este sentido, nos parece especialmente relevante el uso potencial de los nuevos sistemas de autoedición y el uso de internet en las estrategias de promoción del deporte para todos.

Creemos que es altamente significativo el hecho de que hasta un total del 30\% de las experiencias analizadas declaren utilizar internet y ello proviniendo de países tan distintos por su nivel de desarrollo como Grecia, Ecuador, Cuba, China, Brasil, Lituania, Eslovenia, Singapur o Estados Unidos, Japón y Gran Bretaña.

\section{INTERNET. NUEVO INSTRUMENTO PARA LA PROMOCIÓN DEL DEPORTE PARA TODOS}

Entre las nuevas posibilidades abiertas por las tecnologías de la comunicación, aquí debemos prestar una atención muy especial a las que ofrece internet.

Esto no significa, desde luego, que debamos olvidarnos de las múltiples lagunas y desequilibrios existentes en este sector. Los cuadros que adjuntamos sobre implantación del uso de internet a escala mundial (véase el cuadro $\mathrm{N}^{\circ} 2$ ) y sobre los obstáculos existentes en el uso de estas tecnologías expresan claramente la importancia de estas limitaciones. 


\section{Cuadro $\mathrm{N}^{\circ} 2$ \\ Usuarios de internet \\ Estimados en 1997}

Usuarios en millones Población conectada

\begin{tabular}{lrr}
\hline Estados Unidos & 60 a 75 & 20 a $25 \%$ \\
Europa & 23 a 29 & 5 a $10 \%$ \\
América Latina & 8,5 & 1 a $2 \%$ \\
África & 0,8 & 0,09 a 0,1 \\
\hline
\end{tabular}

Fuentes: Diversas. Datos estimados.

Pero lo cierto es que las nuevas lógicas de mediación y las nuevas facilidades de producción y difusión de la información en internet, determinan un fenómeno de gran transcendencia en las modernas formas de comunicación social, con importantes repercusiones en la organización de la comunicación en el mundo del deporte.

Con las nuevas tecnologías de la información las instituciones tienen cada dia mayores facilidades para crear sus propios "medios de comunicación". Se tiende así a romper con la tradicional diferencia de roles entre los medios que "informan de los demás" y los sujetos sociales de la información. Internet pone ahora, al alcance de todas las instituciones, la posibilidad de crear sus propios medios de comunicación, utilizando, en beneficio de sus estrategias, la privilegiada información de la que disponen.

También debe señalarse que estas nuevas tecnologías pueden favorecer muy especialmente los procesos de comunicación destinados a grupos reducidos, que ahora ven la posibilidad de utilizar todas las técnicas y los lenguajes de comunicación en sus procesos. Es la era de la multimedia al alcance, incluso, de la actividad doméstica.

También es necesario destacar que estas tecnologías están experimentando un progreso y una aceleración verdaderamente excepcionales en la historia de las tecnologías de la comunicación. No es únicamente el número de webs y de páginas de contenido lo que crece espectacularmente en internet, día tras día, sino que también se produce una notable aceleración en el incremento del número de usuarios. Todo ello impulsado por el proceso (irreversible) de digitalización de la telefonía que caracteriza a la comunicación de este final de siglo. 
Sería inconcebible no prestar la máxima atención a estas nuevas posibilidades tecnológicas para el desarrollo de proyectos educativos, como es el caso de la promoción del deporte para todos.

En la nueva era de la comunicación todas las instituciones con finalidades educativas deberán descubrir cómo ellas mismas pueden convertirse en verdaderos medios de comunicación.

$\mathrm{Y}$ esto no únicamente en relación con internet, sino también con las nuevas técnicas de impresión y edición. Las estrategias de comunicación del deporte para todos o, si se quiere, las experiencias minoritarias de promoción del deporte, pueden ahora beneficiarse de las nuevas tecnologías de comunicación adaptadas a sus públicos y necesidades. Un 91\% de las experiencias de deporte para todos analizadas en la base de datos Edusport declaran utilizar impresos de difusión reducida en sus estrategias.

En relación con internet, además de considerar los obstáculos tecnológicos y los desequilibrios ya mencionados, hemos de considerar también la pobreza y limitación de los contenidos disponibles, los obstáculos económicos, cada día más generalizados, al acceso universal a los contenidos disponibles, pero sobre todo, la incapacidad de muchas instituciones para adaptarse a las nuevas condiciones de la comunicación en la sociedad informacional.

\section{El deporte, tema destacado en internet}

Ya en la actual primera fase de expansión de internet, el deporte se ha convertido en una de sus secciones o temáticas centrales. De hecho, el ítem "deporte" se encuentra, invariablemente, entre los ítems básicos de todos los buscadores universales (Yahoo, Infoseek, Lycos, AOL, etc.). De hecho, lo que se está produciendo en internet es la aparición de verdaderos nuevos multimedia deportivos on line. Véase, por ejemplo, el Chanel Sports de Infoseek (http://sports.infoseek.com/Topic/Sports/) o el programa World Sport de la agencia Reuters (http:/ /www.sportsweb.com/) o la oferta internet sobre deporte de los grandes broadcasters internacionales como la CNN/Sport Ilustrated (http://www.cnnsi. com/), la MS/NBC http://www.msnbc.com/) o, en Europa, la BBC (http://news.bbc.co.uk/hi/english/sport/) o la RAI. (http://www.raisport.rai.it/).

Pero la información deportiva en internet también se desarrolla en otras instancias, al margen de los medios de 
comunicación convencionales, con la aparición de nuevos webs deportivos originados en las instituciones deportivas.

Así vemos cómo los clubes, las federaciones y los organizadores de grandes acontecimientos deportivos se convierten, también ellos, en verdaderos medios de comunicación. Ya no es extraño ver anuncios de webs (por ejemplo "www. uefa.com") en la publicidad de los estadios y probablemente no tardaremos mucho en ver la dirección de una web en la camiseta de algún equipo deportivo.

En 1998, cerca del 70\% de las federaciones internacionales olímpicas disponían de web propia, algunas de ellas con todos los requisitos de los grandes multimedia deportivos. Los grandes clubes -FC Barcelona (http://www. fcbarcelona.es/), Chicago Bulls (http://www.nba.com/ bulls/index.html), Manchester United (http://www.manutd. com/) disponen de webs propias con índices de acceso millonarios-.

Lo mismo sucede ya con los grandes acontecimientos deportivos, tales como los mundiales de fútbol (http://www. france98.com/), el Tour de Francia (http://www.tourvoile. $\mathrm{fr} /$ ), el torneo de Wimbledon (http://www. wimbledon-fc. com/) o el Superbowl (http://www.superbowl.com/).

Un caso especialmente relevante lo constituyó la web de los Juegos Olímpicos de Invierno en Nagano '98, que 1legó hasta los 634.000.000 hits o accesos de usuarios, cifra récord hasta hoy sólo superada por la publicación en internet del Informe Starr (véase cuadro $N^{\circ} 3$ ).

\section{Cuadro $\mathrm{N}^{\circ} 3$ \\ Número de hits de la web oficial de Nagano 1998 (www.nagano.olympic.org)}

\begin{tabular}{lcccc}
\hline & $\begin{array}{c}\text { Número } \\
\text { de hits } \\
\text { (total, 16 días) }\end{array}$ & $\begin{array}{c}\text { Número } \\
\text { de hits } \\
\text { por día }\end{array}$ & $\begin{array}{c}\text { Máximo } \\
\text { número de } \\
\text { hits (minuto) }\end{array}$ & $\begin{array}{c}\text { Páginas } \\
\text { contenido }\end{array}$ \\
\hline Atlanta '96 & 185.800 .000 & 11.000 .000 & & \\
Nagano '98 & 634.000 .000 & 39.700 .000 & 110.414 & 48.493 \\
\hline
\end{tabular}

Fuente: José Luis Iribarren, Prg. Director Internet Strategy, IBM, 1998.

Según datos de IBM, el Nagano's Official Web-Site alcanzó 634 millones de hits durante los 16 días del aconteci- 
miento, con el récord de 110.414 hits por minuto el día 2 de febrero, coincidiendo con el Figure Skating y el Ice Hockey.

La experiencia de la web oficial de Nagano también nos suministra algunos datos interesantes sobre el origen de los usos de internet a escala mundial. Se evidencia una destacadísima presencia de usuarios de Estados Unidos (56,8\%), una presencia muy especial de usuarios japoneses (24\%), dejando así constancia de la importancia del factor local, y una más bien limitada presencia de usuarios europeos $(16,7 \%)$.

Fuera de estos países, más desarrollados tecnológicamente, las consultas a Nagano son limitadas o prácticamente inexistentes $(2,5 \%)$. Se pone así de relieve los grandes desequilibrios en la implantación de internet y la inconveniencia de referirnos a este medio como un verdadero mass media de cobertura mundial.

¿Cuál es el estado de la cuestión en 1998?

El análisis de la información olímpica disponible en internet, y de su evolución, nos pone de manifiesto algunas posibilidades y logros, pero también importantes lagunas y contradicciones.

Por una parte, la existencia de grandes proyectos, especialmente las grandes webs oficiales de los Juegos Olímpicos, $y$, por otra, la lentitud en adaptar a la nueva era internet aspectos elementales y básicos de la información deportiva y olimpica.

En contraste con la gran cantidad de páginas web existentes en internet (véase cuadro $\mathrm{N}^{\circ} 4$ ) en las que aparece el item "Olympic", la presencia de las instituciones olimpicas en la red puede calificarse, todavia, de muy limitada. Aparte de las webs del Comité Olímpico Internacional (COI) y de los comités de organización, que merecen un comentario aparte, es significativo el escaso porcentaje de comités nacionales olimpicos que disponen de web propia en comparación con las federaciones internacionales (véase cuadro $\mathrm{N}^{\circ} 5$ ). En nuestra última investigación (setiembre de 1998) el porcentaje de federaciones internacionales que ya disponian de web representaba el $100 \%$ del total, mientras que el número de comités olímpicos nacionales presentes en internet había crecido muy poco respecto del año anterior y se situaba en un escaso $21 \%$ de su total. 


\section{Cuadro $\mathrm{N}^{\circ} 4$}

Información olímpica en internet. Mayo 1998

Número de páginas localizadas por ítems

\begin{tabular}{lrrrr}
\hline & Hotbot & Infoseek & Excite & Altavista \\
\hline Olympic & 375.524 & 228.479 & 129.766 & 949.210 \\
Olympics & 280.018 & 134.974 & 80.140 & 566.690 \\
Olympism & 514 & 209 & 180 & 479 \\
\hline
\end{tabular}

Fuente: Centre d'Estudis Olímpics i de l'Esport. UAB, Barcelona.

Elaboración propia.

Cuadro $N^{\circ} 5$

Instituciones olímpicas que disponen de web

(1997-1998)

\begin{tabular}{lcccc}
\hline & $\begin{array}{c}\text { Mayo } \\
\mathbf{1 9 9 7}\end{array}$ & $\begin{array}{c}\text { Mayo } \\
\mathbf{1 9 9 8}\end{array}$ & $\begin{array}{c}\text { Setiembre } \\
\mathbf{1 9 9 8}\end{array}$ \\
\hline Federaciones internacionales & $54 \%$ & $68 \%$ & $100 \%$ & (34 websites) \\
Comités nacionales olímpicos & $17 \%$ & $18 \%$ & $21 \%$ & $(41$ websites $)$ \\
\hline
\end{tabular}

Fuente: Centre d'Estudis Olímpics i de l'Esport. UAB, Barcelona.

Elaboración propia

Del conjunto de webs olimpicas debemos destacar, finalmente, el escaso desarrollo de proyectos educativos que hayan sabido aprovechar el extraordinario potencial educativo de la red y de sus tecnologías.

\section{ALGUNAS CONCLUSIONES. LA PROMOCIÓN DEL DEPORTE PARA TODOS ANTE LAS NUEVAS CONDICIONES DE LA COMUNICACIÓN}

Al formular algunas conclusiones, quisiéramos empezar por señalar las responsabilidades que corresponden a las instituciones deportivas en este terreno, para analizar posteriormente las responsabilidades que puedan corresponder a los mass media. 
1. Sobre las responsabilidades de las instituciones deportivas

Los promotores del deporte para todos deberán adaptarse necesariamente a las condiciones de espectacularidad de la comunicación moderna y a la agenda temática propia de los mass media, sin renunciar a los objetivos y valores educativos del deporte.

Se debe tener en cuenta que la ausencia de referencias al deporte para todos en los medios de comunicación no siempre es consecuencia de una falta de interés por parte de éstos. La responsabilidad de esta ausencia debe atribuirse también a la falta de proyectos y de flujo de informaciones por parte de las instituciones deportivas dirigidos a los mass media.

Para la consecución de estos fines las organizaciones deportivas deberian establecer programas de colaboración de alcance nacional e internacional, con el objeto de gestionar y coordinar sus recursos de marketing y de comunicación. Pero, especialmente, las instituciones deportivas deberian potenciar el uso de las nuevas tecnologías, creando sus propios medios de comunicación, especialmente en lo que respecta a la autoedición y a la utilización de internet.

Es necesario hacer un llamado a la responsabilidad de las instituciones deportivas más influyentes y con mayores recursos -comités olímpicos, grandes clubes, federaciones, ligas profesionales- en relación con la defensa y la promoción del deporte para todos. Estas instituciones deportivas son las primeras beneficiarias de la atención de los medios por el deporte $y$, por tanto, son también las principales responsables de la producción de símbolos en el deporte contemporáneo.

Estas instituciones deportivas, gracias a la atención que les prestan los mass media, se han convertido en las principales productoras y difusoras de imágenes sobre el deporte. Las competiciones deportivas son ahora grandes escenarios en los que se generan las imágenes y las ideas sobre el comportamiento deportivo: tolerancia, cooperación, fair play, amistad o, por el contrario, intolerancia, enemistad, violencia, trampas, antideportividad, etc.

Las ceremonias olimpicas constituyen el mejor ejemplo positivo de esta producción de símbolos, pero existen otros múltiples ejemplos, positivos y negativos, en los comportamientos cotidianos de atletas, entrenadores y dirigentes ante las cámaras. Las instituciones deportivas de elite son ahora los principales pedagogos o antipedagogos del deporte. 
Esta responsabilidad debe extenderse a los atletas y jugadores que ejercen una gran influencia sobre los más jóvenes, y todo ello a escala planetaria.

El análisis cultural del fenómeno deportivo moderno justifica plenamente que, desde las instancias académicas, reclamemos a las grandes instituciones deportivas un compromiso con la educación deportiva, evitando la producción de símbolos de exclusión, insolidaridad o violencia, utilizando para estos fines las nuevas tecnologias de la información, especialmente internet.

\section{Sobre las responsabilidades de los mass media}

Una de las piezas básicas del sistema democrático es la libertad de expresión y el derecho de los ciudadanos a una crítica responsable. Pero ésta es también la principal misión de los medios de comunicación en defensa de los valores del deporte y del deporte para todos. Para ello los medios de comunicación deben mantener su independencia, lo que es cada vez más dificil, respecto de las instituciones deportivas.

La crítica de los medios es fundamental para el futuro del deporte: denunciando los abusos y desigualdades, las corrupciones, las manipulaciones comerciales, evitando la presión sobre los atletas, luchando contra el doping y sus orígenes, poniendo al descubierto los comportamientos inciviles y violentos que puedan producirse en el mundo del deporte. La crítica periodística es un elemento clave, insustituible, de la defensa de los valores sociales del deporte.

Sin embargo, el análisis de contenido de los medios de comunicación deportivos no resiste la evidencia de múltiples lagunas, desigualdades y desequilibrios que deben ser denunciados y corregidos.

Lagunas respecto de los deportes minoritarios y del deporte para todos, desigualdades en el tratamiento del deporte de hombres respecto del deporte de mujeres, desequilibrios en el tratamiento de los deportes televisivos respecto de los deportes no televisivos.

Desde el mundo del deporte debe reclamarse a los medios de comunicación -muy especialmente a los medios públicos de comunicación- un mayor compromiso con los aspectos educativos y sociales del deporte. Los mass media crean el lenguaje del deporte, establecen sus estereotipos. Son, sin duda, corresponsables de la "cultura" del deporte en la sociedad moderna.

Finalmente, se debe señalar que las instituciones educativas y académicas también tienen sus responsabilidades 
y compromisos en relación con el deporte. Este compromiso pasa por la introducción del tema del deporte en sus aulas y en sus bibliotecas como un objeto de estudio. La consideración del deporte como un fenómeno cultural, objeto de estudio en las escuelas y universidades, constituye un aspecto fundamental de la defensa de los valores sociales y humanísticos del deporte que aquí postulamos. 